\title{
Lichen Nitidus Associated with Onychodystrophy and Response to Therapy: Report of Two Cases
}

\author{
Vandana Kataria $^{a}$ Archana Singal $^{a}$ Vinod K. Arora ${ }^{b}$ \\ a Department of Dermatology and Sexually Transmitted Diseases, University College of Medical Sciences and GTB \\ Hospital (University of Delhi), Delhi, India; ${ }^{b}$ Department of Pathology, University College of Medical Sciences and \\ GTB Hospital (University of Delhi), Delhi, India
}

\section{Established Facts}

- Nail involvement in lichen nitidus (LN) is rare.

- Nail changes described so far in association with LN include pitting, longitudinal ridging, and trachyonychia.

\section{Novel Insights}

- We describe two children with LN-associated onychopathy that included nail plate splitting and crumbling in addition to longitudinal ridging/trachyonychia.

- Nail changes showed significant improvement to intramatricial triamcinolone acetonide injections in one child.

\section{Keywords}

Lichen nitidus · Onychodystrophy · Intramatricial injection

\section{Abstract}

Lichen nitidus (LN) is a chronic inflammatory condition characterised by multiple asymptomatic shiny, flat-topped, pale to skin-coloured tiny papules. LN occurs most often in children and young adults with limbs, abdomen, chest, and penile shaft as common sites of predilection. Nail involvement is rare and includes irregular longitudinal grooving and ridg- ing of the nail plate. We report two cases of generalised LN with nail dystrophy in 8-and 12-year-old boys along with the treatment response and review the pertinent literature.

(c) 2018 S. Karger AG, Basel

\section{Case Reports}

Case 1

An 8-year-old boy presented with dystrophy of the right finger nail of 2 months' duration. The nail changes were preceded 6 months back by asymptomatic skin lesions that appeared in
(C) 2018 S. Karger AG, Basel

E-Mail karger@karger.com

www.karger.com/sad
Prof. Archana Singal

University College of Medical Sciences and GTB Hospital Delhi 110095 (India)

E-Mail archanasingal@ hotmail.com 
Fig. 1. a Multiple pinhead-sized, skin-coloured, shiny extrafollicular papules distributed over the bilateral arms, forearms, trunk, and lower limbs. b Shiny papules overlying the distal phalanx and periungual area of the fingernails. The right index finger nail has ragged cuticle and nail plate splitting with dystrophic medial half without any evidence of pterygium formation.
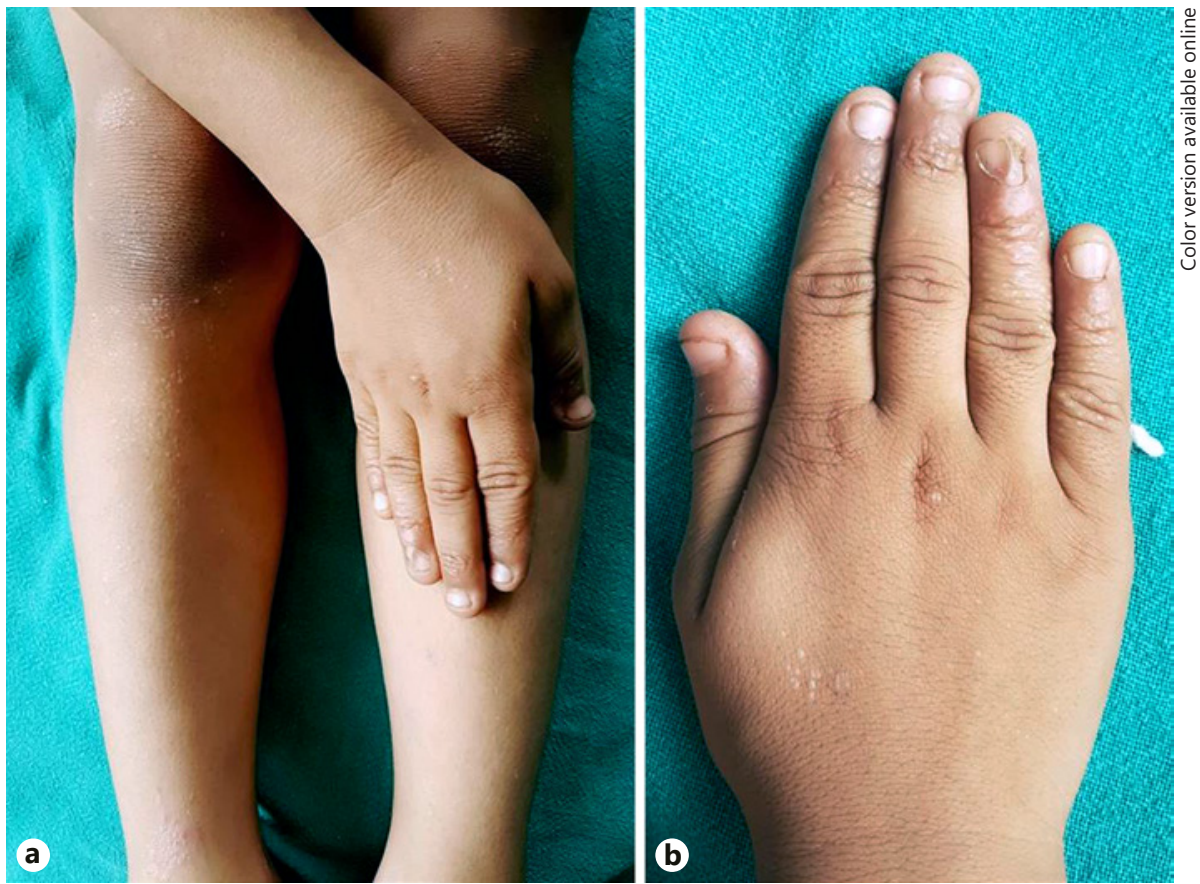

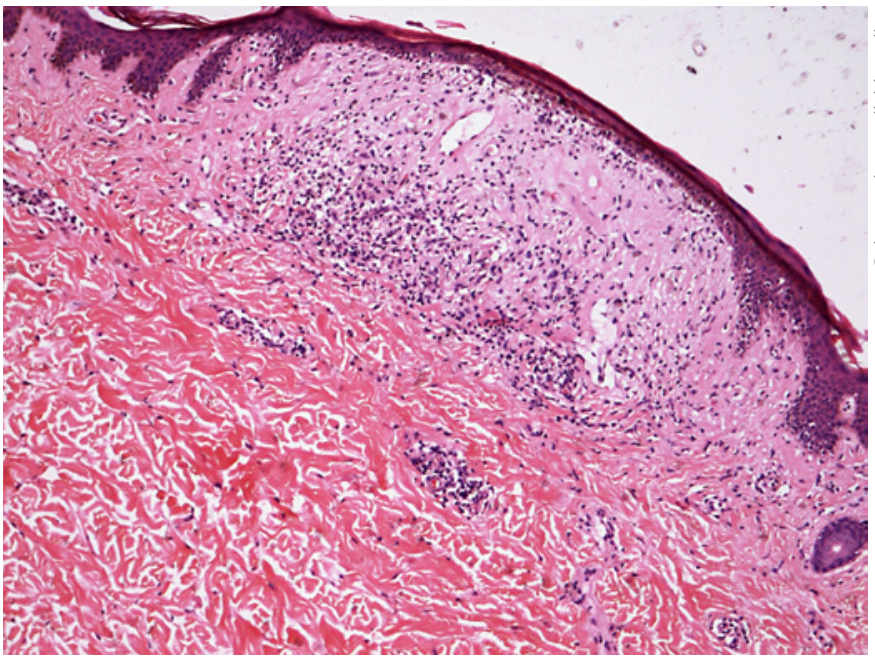

Fig. 2. Well-circumscribed papillary dermal lymphoplasmacytic cellular infiltrate surrounded by elongated rete ridges.

crops first over the trunk followed by involvement of all limbs and the face. Cutaneous examination revealed multiple pinhead-sized, skin-coloured, shiny extrafollicular papules over the face, bilateral arms, forearms, trunk, lower limb (Fig. 1a), and penile shaft. These lesions were discrete as well as grouped with evidence of koebnerisation at places. Examination of the nail unit showed presence of shiny papules overlying distal phalanx of all fingernails and in the periungual region of the right ring finger (Fig. 1b). This nail had ragged cuticle and showed nail plate splitting with dystrophic medial half but without any evidence of pterygium formation. Hair, mucosae, palms, and soles were not involved. Histopathology from the skin lesion showed hyperkeratosis and parakeratosis in the epidermis with a well-circumscribed, papillary dermal lymphoplasmacytic cellular infiltrate within a few rete ridges consistent with the diagnosis of lichen nitidus (LN) (Fig. 2). Based on the clinical and histopathological features, a diagnosis of generalised LN with nail dystrophy was made. The patient's guardian was counselled about the benign nature of the disease with potential of spontaneous resolution. The boy was prescribed emollient application for the skin and moderate potency topical steroid for the involved fingernail, with appreciable improvement within 3 months.

\section{Case 2}

Our second patient was a 12 -year-old boy who noticed roughening of the bilateral big toenails and the right second toenail. About 2 months later, the patient noticed development of mildly itchy pinhead-sized skin lesions. Examination revealed pinheadsized, shiny papular lesions with positive Koebner's phenomenon over the dorsa of the hands, forearms, chest, and external genitalia, classical of LN. The bilateral big toenails and the right second toenail showed longitudinal ridging, thickening, and pigmentation (Fig. 3a). The right thumbnail had longitudinal ridging, nail plate thinning, and a Beau's line (Fig. 3b). He also had erythematous and pale rough coalescing plaques over the central palms. A clinical diagnosis of LN with nail dystrophy was made. The patient was counselled about the benign course of the skin and nail lesions. He was very distressed about the nails and insisted on treatment. Therefore, two injections of intramatricial triamcinolone acetonide $(5 \mathrm{mg} / \mathrm{mL})$ were given at a monthly interval in the big toenails with significant improvement at 4 months (Fig. 4). 
Fig. 3. a Dystrophic nails of the bilateral toes and the right second toe. Note LN lesions on the dorsa of hands and digits. b Longitudinal ridging in both thumbnails and Beau's line in the right one, along with LN lesions. LN, lichen nitidus.
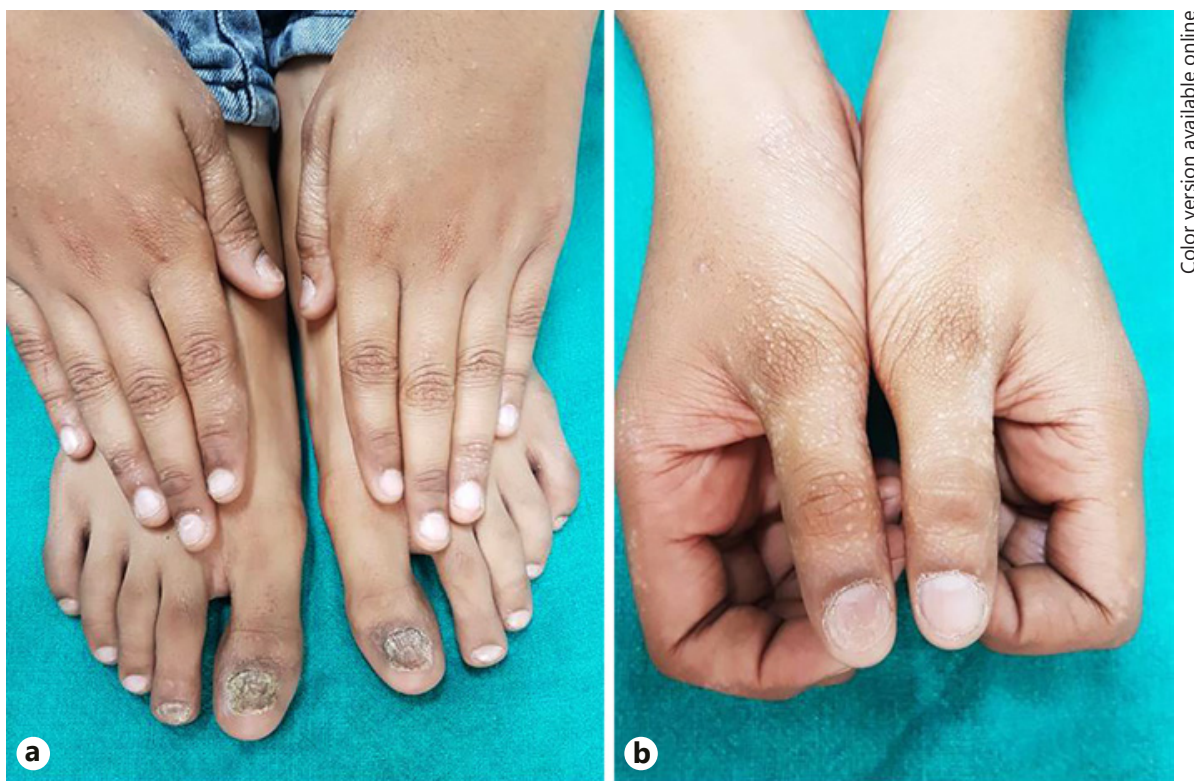

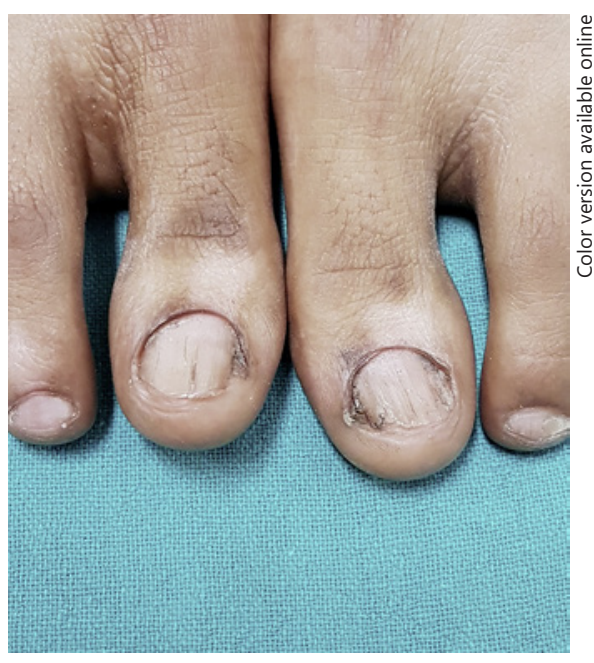

Fig. 4. Case 2 after two sessions of intramatricial injection therapy.

\section{Discussion}

LN is an uncommon inflammatory disorder described in children and commonly involves the limbs, abdomen, trunk, and penile shaft [1]. It is uncommon for LN to involve the mucous membranes, palms, soles, and nails. Nail involvement is rare and tends to be associated with the generalised disease variant. Presence of longitudinal grooves and ridges on the nail plate has been reported with LN [2]. Nail folds can be involved, with the presence of nonspecific periungual inflammation or violaceous shiny papules in the majority of cases [3].

An extensive English-language literature search revealed that there are handful of cases published so far of LN associated with nail changes (Table 1) [4-7]. Clinically, the nail changes associated with LN and lichen planus may be related to each other. In contrast to lichen planus, nail changes in LN are rare and less severe, with no pterygium formation or anonychia [3]. Patients with LN and nail changes have a higher frequency of palmar involvement, and it was observed in one of our two cases. LN-associated onychodystrophy more often occurs in children, and both the cases reported here are children. Since LN is asymptomatic, treatment is usually not necessary and is required only for symptomatic and cosmetically disturbing lesions. Topical midpotency corticosteroids, topical calcineurin inhibitors, NBUVB, and PUVA are usually considered effective modalities of treatment. Intramatricial injections of steroid may be extremely useful in select cases where the involvement is severe. It can be proposed that nail changes in LN result from the inflammation of the nail matrix.

Nail changes in LN are associated with extensive cutaneous disease. Nail lesions tend to be less severe than those seen in lichen planus and are often self-limiting. The condition is being reported because of its rare occurrence and response to injection therapy. 
Table 1. Lichen nitidus with nail involvement

\begin{tabular}{|c|c|c|c|c|c|}
\hline $\begin{array}{l}\text { Reference } \\
\text { (first author) }\end{array}$ & $\begin{array}{l}\text { Age, years/ } \\
\text { sex }\end{array}$ & Nail plate changes & $\begin{array}{l}\text { Onset of nail changes } \\
\text { and skin lesions }\end{array}$ & Treatment & Outcome (nails) \\
\hline Kellett [4], 1984 & $7 / \mathrm{F}$ & pits, rippling & concurrent & not specified & not specified \\
\hline $\begin{array}{l}\text { Natarajan [5], } \\
1986\end{array}$ & $9 / \mathrm{F}$ & $\begin{array}{l}\text { trachyonychia, longitudinal } \\
\text { ridges, rippling }\end{array}$ & concurrent & none & no improvement \\
\hline Munro [6], 1993 & $\begin{array}{l}\text { (a) } 53 / \mathrm{M} \\
\text { (b) } 37 / \mathrm{F}\end{array}$ & $\begin{array}{l}\text { (a) pits, ridges } \\
\text { (b) longitudinal ridges, } \\
\text { distal splitting }\end{array}$ & not specified & $\begin{array}{l}\text { (a) not specified } \\
\text { (b) none }\end{array}$ & $\begin{array}{l}\text { (a) not specified } \\
\text { (b) not specified }\end{array}$ \\
\hline Bettoli [7], 1997 & $10 / \mathrm{M}$ & $\begin{array}{l}\text { pits, longitudinal and } \\
\text { transverse ridges }\end{array}$ & not specified & none & $\begin{array}{l}\text { resolved within } \\
6 \text { months }\end{array}$ \\
\hline Tay [3], 2015 & $4 / \mathrm{F}$ & $\begin{array}{l}\text { median canaliform dystrophy, } \\
\text { trachyonychia }\end{array}$ & $\begin{array}{l}\text { nail changes preceded } \\
\text { skin lesion }\end{array}$ & $\begin{array}{l}\text { mometasone furoate } 0.1 \% \\
\text { cream }\end{array}$ & $\begin{array}{l}\text { treatment interrupted } \\
\text { by parents }\end{array}$ \\
\hline $\begin{array}{l}\text { Albayrak [2], } \\
2017\end{array}$ & $5 / \mathrm{M}$ & trachyonychia & concurrent & $\begin{array}{l}\text { topical corticosteroid for skin } \\
\text { lesions }\end{array}$ & not specified \\
\hline Our case 1 & $8 / \mathrm{M}$ & $\begin{array}{l}\text { longitudinal grooving, irregular } \\
\text { ridging }\end{array}$ & $\begin{array}{l}\text { skin lesions preceded } \\
\text { nail changes }\end{array}$ & $\begin{array}{l}\text { emollient for skin lesions and } \\
\text { mild topical steroid for finger } \\
\text { nail }\end{array}$ & $\begin{array}{l}\text { mild improvement in } \\
\text { skin lesions as well as } \\
\text { affected nail }\end{array}$ \\
\hline Our case 2 & $12 / \mathrm{M}$ & $\begin{array}{l}\text { trachyonychia, ridging, Beau's } \\
\text { line }\end{array}$ & $\begin{array}{l}\text { nail lesions preceded } \\
\text { skin lesions }\end{array}$ & $\begin{array}{l}\text { emollient for skin lesions, } \\
\text { intramatricial injection of } \\
\text { triamcinolone acetonide in } \\
\text { toenails } 5 \mathrm{mg} / \mathrm{mL}\end{array}$ & $\begin{array}{l}\text { significant } \\
\text { improvement }\end{array}$ \\
\hline
\end{tabular}

\section{Statement of Ethics}

Written informed consent was obtained from the parents of both patients.

\section{Disclosure Statement}

The authors declare that they have no conflict of interest regarding this paper. They have no financial disclosure to make.

\section{References}

1 Gandhi V, D’Souza P, Gujral S, Ramam M. Lichen nitidus of palms and soles. Indian J Dermatol Venereol Leprol. 1998 Jan-Feb; 64(1):34-6.

2 Albayrak H, Yanık ME, Erfan G, Oznur M, Kulac M. Lichen nitidus presenting with trachyonychia. Indian J Dermatol Venereol Leprol. 2017 Jul-Aug;83(4):516.
3 Tay EY, Ho MS, Chandran NS, Lee JS, Heng YK. Lichen nitidus presenting with nail changes - case report and review of the literature. Pediatr Dermatol. 2015 May-Jun;32(3): 386-8.

4 Kellett JK, Beck MH. Lichen nitidus associated with distinctive nail changes. Clin Exp Dermatol. 1984 Mar;9(2):201-4.

5 Natarajan S, Dick DC. Lichen nitidus associated with nail changes. Int J Dermatol. 1986 Sep;25(7):461-2.
6 Munro CS, Cox NH, Marks JM, Natarajan S. Lichen nitidus presenting as palmoplantar hyperkeratosis and nail dystrophy. Clin Exp Dermatol. 1993 Jul;18(4):381-3.

7 Bettoli V, De Padova MP, Corazza M, Virgili A. Generalized lichen nitidus with oral and nail involvement in a child. Dermatology. 1997;194(4):367-9. 